Artigos

\title{
El dinero: organizador social de la ciudad de Pichari $^{2}$
}

Sofía Isabel Vizcarra Castillo²

Resumo: A cidade de Pichari, no principal vale produtor de coca do Peru, conhece um boom econômico ligado a um segundo boom do narcotráfico. $\mathrm{Na}$ cidade, existe uma coexistência diária entre atores ligados às esferas econômicas legais e ilegais. Como ocorrem as interações? Como os cidadãos concordam fazer trocas com atores ilegais? Empregando métodos qualitativos, se analisa a circulação do dinheiro na cidade para demostrar como ela permite uma coabitação pacífica entre os diferentes atores da cidade. Nesse sentido o dinheiro é organizador social da cidade.

Palavras-chave: Sociologia econômica; Moral; Dinheiro; Narcotráfico; Peru.

\section{Money: Pichari's social organizer}

Abstract: The city of Pichari, located in Peru's main coca-producer valley, knows an economic boom linked to a second boom of drug trafficking. There is a daily coexistence between actors linked to the legal and illegal economic spheres. How do these interactions occur? How people accept to interact with illegal actors? Based on qualitative methods, I use money analysis, considered as a social organizer, to

\footnotetext{
1 Investigación financiada por el Premio de Apoyo a la Investigación de Posgrado 2017 de la Pontificia Universidad Católica del Perú (PUCP).

2 Departamento de Ciencias Sociales - Pontificia Universidad Católica del Perú (PUCP) - Lima - Perú sofia.vizcarra@pucp.edu.pe
} 
show how its circulation allows pacific cohabitation between the different actors of the city.

Keywords: Economic Sociology; Moral; Money; Drug-trafficking; Peru.

Resumen: La ciudad de Pichari, ubicada en el principal valle cocalero del Perú, conoce un auge económico vinculado a un segundo boom del narcotráfico. Allí existe una convivencia cotidiana entre actores vinculados a las esferas económicas legales e ilegales. ¿Cómo se dan las interacciones? ¿Cómo se acepta relacionarse con actores ilegales? A partir de métodos cualitativos, se emplea la pista de análisis del dinero, considerado como organizador social, para mostrar como su circulación permite una cohabitación pacifíca entre los diferentes actores de la ciudad.

Palabras Clave: Sociología económica; Moral; Dinero; Narcotráfico; Perú

En la ciudad de Pichari, en el corazón del principal valle cocalero del Perú, no hay coca, hay dinero, mucho dinero. La hoja de coca y la cocaína no se cultivan o refinan en la ciudad, ellas llegan y circulan en la ciudad transformadas en dinero. Si en las zonas rurales, como lo describe el antropólogo Enrique Mayer (2004: 202-5), la hoja de coca era el lubricante de las relaciones de reciprocidad, en las ciudades modernas de los valles cocaleros las relaciones sociales pasan a ser intermediadas principalmente por el dinero. La ciudad de Pichari, ubicada en la provincia de la Convención, departamento de Cuzco en el Valle de los Ríos Apurímac, Ene y Mantaro (VRAEM), conoce desde los años 2000 un segundo boom del narcotráfico con el crecimiento de los cultivos de coca en el valle. Este boom corresponde a una etapa de crecimiento urbano y económico vinculado al incremento de la presencia de los servicios estatales, así como la expansión de los comercios y servicios del sector privado. Así, en la actualidad Pichari cuenta con alrededor de 12,000 habitantes, duplicando su población con respecto al censo de 1993. El desarrollo de las funciones administrativa y comercial de la ciudad, está directamente ligado a tres fuentes de dinero: los recursos provenientes del narcotráfico, los recursos ligados a la inversión del Estado en la lucha contra esta actividad y las regalías por el canon gasífero ${ }^{3}$ que ha recibido el distrito en los últimos años.

3 Al encontrarse en la provincia de La Convención dónde se encuentra ubicado el yacimiento de gas natural "Camisea", a Pichari, a pesar de no tener yacimientos gasíferos, también le corresponde recibir regalías por canon gasífero. 
El análisis aquí propuesto se centra en las interacciones cotidianas entre personas vinculadas a las esferas económicas legal (formal e informal) e ilegal, las cuales son porosas y muchas veces difíciles de diferenciar en las prácticas cotidianas. ¿Cómo se dan estas interacciones? ¿Qué surge de ellas en relación a las percepciones sobre las actividades ilegales? La pista elegida para este análisis es el dinero ya que tiene el carácter de organizador social (Wilkis, 2013: 25) por lo que permite explorar la construcción del orden social local. Además, algunos autores lo consideran como un hecho social total (Mauss, 2016; Wilkis, 2013) que permite aproximarse a las diversas esferas de la vida de un individuo (personal, laboral, social etc.), especialmente en contextos urbanos en creciente modernización y monetarización.

En contextos con una fuerte presencia de actividades económicas ilegales, la pista del dinero permite indagar sobre es el rol que cumple este último como conector entre las esferas legales e ilegales, permitiendo fluidez en la circulación entre esferas económicas que solo están separadas en teoría pero no en la práctica. Tan solo en Pichari, el tráfico ilícito de drogas mueve alrededor de 17 millones de dólares anuales 4 , por lo que se le considera un motor de la economía. A pesar de que las estimaciones internacionales plantean que solo una pequeña fracción de ese valor realmente se queda en las zonas productoras (OEA, 2013: 21), ello es suficiente para que a nivel local se le considera un motor de la economía.

El narcotráfico como actividad económica es particularmente importante para las zonas rurales y las zonas urbanas que dependen del campo, como lo señala Valencia (2016: 67-68). El narcotráfico conecta a los valles cocaleros y a sus ciudades al mercado, los revaloriza como centro productivo (de una economía ilegal) y como centro de inversión. Por lo tanto, logra que exista un flujo constante de dinero que circule entre los diferentes emprendimientos económicos de la ciudad. A través de diversos mecanismos, parte de ese dinero se inserta en la economía de la ciudad y termina por generar espacios de cohabitación entre los actores que pertenecen a las diferentes esferas de la vida económica.

El dinero anima la dinámica social de la ciudad. A partir de esta constatación surgen preguntas que apuntan al rol de intermediación que cumple el dinero:

4 Para el año 2015, existían 18, 333 hectáreas cultivadas de coca en el VRAEM, dentro de las cuales las 2,356 hectáreas cultivadas en el distrito de Pichari (UNODC 2016). Las hectáreas cultivadas en Pichari tienen un potencial de producción de casi 26TM de clorhidrato de cocaína anuales (conversión propia en base a factor no oficial del operativo breakthrough, 2003) con un valor de mercado de más de 29 millones de dólares (utilizando el valor de precio en chacra del kg de cocaína reportado para el año 2015 en el SIMCI. UNODC). 
¿qué significa ganar dinero legítimamente? ¿qué dinero se puede recibir? ¿cuál es mejor rechazar? ¿cómo gastar legítimamente el dinero? El dinero que circula en la ciudad cocalera conecta los diferentes tipos de actores económicos de la ciudad, formales, informales e ilegales. Aunque está clasificación parezca Esta conexión se hace a partir de diversos tipos de piezas ${ }^{5}$ de dinero, como lo denomina Wilkis (2013): el dinero ganado y el dinero gastado, en el primer plano. En Pichari, detrás de estas piezas de dinero se encuentran una heterogeneidad de experiencias en las que se produce la ganancia y el gasto del dinero (Guyer, 2004), muchas de ellas ligadas a esferas ilegales e informales. Sin embargo, en el mercado se juntan estas diversas experiencias detrás de la ganancia del dinero y se disuelven en el anonimato de los intercambios financieros.

Para el recojo de información de esta investigación recurrió a lo que algunos autores denominan como etnografía enfocada (Montes de Oca, 2015), el cual adapta el enfoque tradicional de etnografía malinowskiano a los contextos actuales y los desafíos metodológicos que presentan. Estas adaptaciones incluyen el desarrollo de técnicas especificas como la etnografía multi-situada (Marcus, 1995) o la ampliación a campos no tradicionales de la etnografía como el Estado (Agudo Sanchíz e Estrada Saavedra, 2011; Montes de Oca, 2015). Una estrategia adaptada a la presencia de actividades ilegales en los contextos de investigación consiste en hacer etnografías por periodos breves de tiempo pero en forma repetida con un mismo grupo de autores. La etnografía enfocada al centrarse en un aspecto principal a ser observado puede obtener información relevante en diversas visitas repetidas y no necesariamente de una inmersión prolongada, en el caso de Pichari escogí centrarme en las prácticas económicas de los actores locales. Sin embargo, ello no deja de implicar que el investigador se familiarice con el lenguaje particular del campo e igualmente establezca cierta familiaridad con los participantes de la investigación. Así el trabajo de campo en la ciudad de Pichari se realizó en diversos periodos durante los meses de junio del 2015, febrero del 2016 y agosto del 2016 y julio del 2017.

Los hallazgos aquí presentados recogen las notas de campo realizadas durante las diferente salidas a la ciudad de Pichari. Los actores que pude acompañar fueron comerciantes formales y trabajadores públicos de la ciudad de Pichari. Los seleccioné ya que al estar su actividad principal situada en la esfera económica legal, fue más fácil contactarlos y disminuir los riesgos de exposición

5 El dinero es para Wilkis (2013) movilizador de capital moral en sus diferentes tipos o piezas, como él las denomina. Su clasificación de las diferentes piezas de dinero (ganado, militado, sacrificado, donado y cuidado) son el punto de partida para la reflexión sobre el dinero que realizo en Pichari. 
a actores ilegales. Además esta entrada me permite seguir las prácticas que comienzan en la esfera formal y terminan por conectarse a través del dinero con las otras esferas. Sin embargo esta selección de participantes presenta algunos limites sobre la observación de prácticas económicas ilegales, ya que en muchos casos estas no pudieron ser directamente observadas ya sea por consideraciones de seguridad o porque los propios participantes prefieren no incriminarse directamente, en algunos casos ellos relatan estas prácticas propias o de terceros, pero en otros casos estas prácticas son intuidas o deducidas triangulando los diferentes discursos de los actores. Acompañé a los participantes de la investigación en diferentes espacios públicos y privados de la ciudad. Completé el recojo de información con observación no participante en espacios públicos y entrevistas con habitantes de la ciudad. Para el análisis de dicha información procedí a seleccionar ciertas escenas de la vida cotidiana de la ciudad en las que fuese posible observar la circulación del dinero conectado a diversas esferas económicas. Para tal fin se siguieron las consideraciones del comité de ética de la Pontificia Universidad Católica del Perú. Asimismo, por motivos de seguridad he mantenido el anonimato de los participantes y cambiado sus nombres en los relatos aquí presentados.

\section{Consideraciones teóricas sobre la sociología moral del dinero}

El dinero es un objeto clásico de la sociología, diversos autores se han aproximado a su estudio. El ensayo sobre el don de Mauss (2016) es una obra clásica para aproximarse al estudio del dinero. Es el punto de partida de un largo debate sobre la naturaleza de las transacciones no monetarias. Mauss también sirve como punto de partida para la reflexión sobre el dinero en el contexto de la globalización, ya que insta a diversos sociólogos a interrogarse sobre las nuevas relaciones sociales que se establecen a través del dinero en el marco de la creciente financiarización de la economía.

Para estudiar al dinero desde la sociología económica es necesario comprender la dualidad de su connotaciones tanto como un medio de intercambio anónimo y también como una realidad social (Simiand, 2006). La sociología económica ha desarrollado diversos abordajes sobre el dinero. La sociología clásica que analizaba las transformaciones de las sociedades hacia el capitalismo veía en el dinero una manera de quebrar las relaciones tradicionales de solidaridad como lo sostenían Marx o Simmel.

No obstante, la sociología contemporánea ha aportado otras perspectivas sobre el tema. Así, el trabajo de Zelizer (2011) se contrapone a la visión del 
dinero como un ácido que disuelve la vida social a ver en el dinero un productor de significados que conecta las experiencias subjetivas de las personas (Wilkis, 2013). Como ella misma lo señala: "las personas continuamente están creando distintas clases de dinero. Marcan el dinero y lo incorporan en redes personalizadas de amistades, relaciones familiares e interacciones con las autoridades e incursiones en comercios y negocios" (Zelizer, 2011: 14). La producción de significados a partir de la circulación del dinero es algo que se ha investigado en diferentes contextos.

La conexión moral y emocional del dinero es explorada por diversos autores (Guyer, 2004; Hart, 2007; Parry; Bloch, 1996). Sus múltiples significados invitan a los autores a pensar la heterogeneidad del dinero en sus tipos, usos y lazos que genera (Maurer, 2006; Wilkis, 2013). Así por ejemplo, Hoigard y Finstad (1992) en su estudio sobre la prostitución hace la diferencia entre lo que las prostitutas consideran como dinero "honesto" de aquel que consideran como dinero "sucio". Este último tiene una dinámica de uso diferente del primero relacionado a su origen. En ese sentido aproxima el estudio del dinero al estudio de las redes sociales (Granovetter, 1973; Lomnitz, 1978), en las cuales el rol del intercambio de diversos tipos de capitales (monetario, pero principalmente simbólico) es el punto de partida para el análisis de lo social.

Las investigaciones sobre la sociología moral del dinero pueden dividirse en dos grandes ramas. Por una parte aquellas investigaciones que abordan el rol del dinero en sociedades modernas y altamente monetizadas (Fischer, 2014; Ingham, 2004). Por otro lado, las investigaciones que se han centrado en el estudio del dinero en manos de aquellos considerados como pobres o excluidos (Zelizer, 2011). En Latinoamérica, los cambios que ha generado la globalización económica, así como los procesos de exclusión y segregación han llevado a algunos sociólogos a seguir la pista del dinero para explorar las complejas relaciones sociales que se tejen en los márgenes de las ciudades latinoamericanas, entre aquellos que se denomina popularmente "pobres", desvelando lo que se encuentra detrás del concepto de marginalidad (Muller, 2009; Muller; Wilkis, 2010; Barros; Ossandón, 2012; Damatta; Soarez, 1999; Figueiro, 2012; Müller, 2017; Villarreal, 2009; Wilkis, 2009, 2013). En su exploración de las villas de la periferia bonaerense, Wilkis nos invita a observar a través de sus etnografías las jerarquías morales y tensiones sociales que se construyen por y a través del dinero.

Los estudios sobre el dinero aún son incipientes en América Latina, y más aun en lo relacionado a actividades ilegales. Actualmente, la sociología brasilera viene discutiendo en diversos eventos la posibilidad de que el dinero haya sido un factor de pacificación en la disminución de la tasa de homicidios en 
las favelas de Sao Paulo controladas por el Primeiro Comando da Capital (Feltran, 2014). Sin embargo aún son poco los trabajos que abordan la relación entre dinero y crimen desde una perspectiva micro sociológica. En este artículo propongo retomar dos perspectivas para comprender como el dinero facilita la convivencia entre diferentes actores de la ciudad. Por una parte, la perspectiva moral del dinero para analizar el dinero ganado y por otra parte la perspectiva del dinero como ácido social para el análisis del dinero gastado, donde el mercado disuelve lo problemático detrás del origen del dinero. Así, en Pichari conviven las perspectivas de Zelizer y Simmel como veremos a continuación.

\section{Historias del dinero ganado en la ciudad de Pichari}

La ciudad de Pichari es el teatro en el que se desarrollan las historias detrás del dinero, las prácticas económicas de mercado son el guión y los principales actores de estas prácticas son los habitantes de la ciudad. A ellos los denominaré como clase trabajadora urbana, compuesta tanto por personas asalariadas de los distintos establecimientos de bienes y servicios de la ciudad así como trabajadores públicos, y emprendedores independientes o subempleados que buscan diversas opciones de auto-empleo. También existen en la ciudad miles de personas con empleos temporales y en muchos casos precarios e informales, y ambulantes o transportistas informales quienes complementan sus ingresos trabajando en la cosecha de coca. Sin embargo sección me centraré en aquellas historias de ganancia de dinero de los emprendedores en la esfera formal para mostrar la manera en la que incluso aquellos que se esfuerzan por ganar su dinero "honradamente" lidian con la presencia en el trasfondo del narcotráfico.

Los comerciantes independientes de Pichari, ganan su dinero gracias al consumo que los otros actores de la ciudad realizan en sus locales. A ellos, la circulación constante de dinero les permite tener clientes con un poder adquisitivo creciente, que consumen sus productos y servicios. Incluso algunos tienen estrategias para diferenciar y seleccionar a su clientela a fin de reducir las incertidumbres sobre el tipo de dinero que reciben. Karina ${ }^{6}$, propietaria de una cafetería en la ciudad me comenta un poco sobre su negocio:

Yo he querido crear una cafetería diferenciada aquí. Por eso ofrecemos sándwiches diferentes, jugos y café pasado de aquí mismo. Tampoco vendo

6 Los nombre de las personas y establecimientos han sido modificados a fin de mantener el anonimato y evitar posibles riesgos a la seguridad de los participantes, conforme a lo contemplado en el anexo metodológico validado por el dictamen nº 256-2015/CEI-PUCP del Comité de ética de la PUCP. 
bebidas alcohólicas, excepto cerveza en jarra, ni menú. Si el cliente quiere eso, allí tiene varias opciones por la plaza. Yo quiero tener una buena clientela que siempre vuelva, generalmente los que vienen me conocen a mí o a mis hermanos [...]. Los oficiales vienen a tomar su desayuno americano en vez de desayunar arroz a la cubana. (Notas de campo, Pichari, enero 2016).

Karina gana su dinero con una clientela que en su mayoría le paga con dinero proveniente de un salario del estado. Sin embargo es difícil saber a ciencia cierta la actividad económica de la gente. Como Karina me comentaba, ella no puede discriminar a nadie ni obligar a salir al alguien de su local porque no le inspira confianza. Eso le sucedió una vez:

Una vez llegó un tipo muy prepotente exigiéndome que le haga salchipapa y le sirva cerveza. Yo no sabia muy bien quien era el señor. Tenía sospechas que podía tratarse de alguien involucrado en el negocio [narcotráfico] pero no quise confirmarlo. Le serví rápido la salchipapa y la cerveza en jarra para que se vaya. (Notas de campo, enero 2016).

En esos casos, los comerciantes prefieren tener la menor información posible sobre sus clientes. Mantener la relación estrictamente económica, una transacción de compra-venta sin tener una conversación que prolongue la estadía del cliente incómodo.

Sin embargo para muchos otros comercios de la ciudad no es fácil establecer este tipo de circuito de clientes diferenciados. Karina y otros de los comerciantes lo logran al haber establecido relaciones interpersonales y de confianza con sus clientes, al compartir experiencias de haber vivido en la capital o en ciudades mayores y muchas veces por tener familiares o amigos cercanos trabajando en el Estado. Otros comerciantes no consiguen ser tan selectivos con su clientela. A pesar del constante movimiento económico, no es fácil ser emprendedor en la ciudad. Existe una alta rotación de los negocios. Una hipótesis de esta rotación podría estar relacionada con el hecho de que no siempre es posible generar un volumen de clientes para consolidar un negocio. Si bien es fácil abrir un negocio con dinero legal o ilegal, no siempre es fácil mantenerlo. En algunos otros casos, cuando estos negocios sirven solo como fachada para el lavado de activos, es común que suelan cerrar luego de haber operado por algún tiempo a fin de no despertar sospechas de las autoridades. En un año un local cerca de la plaza pasó de ser bótica ${ }^{7}$ a tienda naturista y luego iglesia evangélica.

7 Bótica es otro nombre bajo el cual se conoce a los negocios de venta de medicamentos en Perú. 
Para emprender en la ciudad es necesario tener acceso a capital para comprar un local o pagar el alquiler adelantado por un año, ello significa contar con al menos diez mil dólares en efectivo para iniciar. Los emprendedores tienen diversas opciones para acceder a ese capital. En primer lugar las instituciones financieras y cajas de ahorro que funcionan a nivel nacional y que brindan acceso al crédito. Varios de los emprendedores con los que pude conversar durante el trabajo de campo habían tenido más de un crédito de negocios en este tipo de institución financiera. Cesar, dueño primero de una botica y luego de un hotel y una cafetería, me comentaba como había hecho para ir expandiendo progresivamente sus negocios:

Para abrir la bótica ahorramos del dinero de la venta de medicamentos, con eso alquilamos el local y también nos compramos este terreno [el terreno donde construyeron el hotel]. Pedí un primer préstamo para construir dos pisos del hotel. Al inicio no había muchas opciones para acceder a crédito, ya después han aumentado pero yo prefiero trabajar con las cajas más conocidas como Caja Huancayo o Señor de Luren. Esas te dan seguridad y me han ofrecido buenas tasas. Luego de construir pedí otro préstamo para construir el edificio del frente. Allí donde funciona la cafetería. Ese préstamo lo sigo pagando pero ya todo es mío. La botica la cerré porque el alquiler ya estaba muy caro. (Notas de campo, Pichari, julio 2017)

La otra opción para conseguir capital es pedir un préstamo a las diferentes entidades financieras locales (cooperativas de ahorro y crédito) que dan facilidades para préstamos. Sin embargo, las autoridades sospechan que estas cooperativas sirven de fachada para el lavado de activos proveniente del narcotráfico, por lo que estos préstamos se realizarían con dinero de origen ilegal que luego ingresa a la economía legal a través del crédito otorgado, un ejemplo la cooperativa investigada en el caso Tormenta ${ }^{8}$ durante el año 2016, que tenía una sede en Pichari.

En algunos casos, hay quienes llegan con dinero en efectivo para alquilar un local, sin especificar como obtuvieron el capital. La policía sospecha que también hay una reinversión directa en la economía legal sin mediación del sistema financiero. Esta reinversión se realiza en diferentes rubros. En algunos casos para abrir negocios que sirvan de fachada para continuar lavando activos

8 Operativo policial contra el lavado de activos, más detalle disponibles en: <https://larepublica.pe/ sociedad/1155206-incautan-18-inmuebles-a-una-red-criminal-de-lavado-de-activos $>$. Acceso en: 20 maio 2019. 
en otros casos para cambiar de rubro de actividad y salir de la actividad ilegal. Así, Demetrio, un asesor de caficultores que conocí en Pichari me comentó la historia de un amigo suyo:

Él tenía su chacra de coca en los noventa, y ahí incluso unos años hubo una poza9. Después del 94, vio que tenía que tener otra cosa, pero siguió con la coca unos años. Ahí me vino a pedir consejo, sabía que yo conocía de café. Se compró varias hectáreas de café, y luego se fue metiendo en el negocio de la exportación. Ahora ya no tiene coca (Notas de campo, Pichari, julio 2017)

En este caso, la ganancia de dinero se realiza en la esfera ilegal pero se reinserta sin problemas en la esfera legal. Esto le permite al emprendedor comenzar por una parte "limpiar" su dinero y por otra parte comenzar a ganar dinero de manera legal a fin de retirarse de la actividad ilegal. Sin embargo, es importante recalcar que para poder ganar dinero en Pichari como comerciante independiente es necesario tener dinero.

Aquellos comerciantes que se esfuerzan por ganar dinero de manera honrada utilizan las siguientes estrategias de distanciación de la actividad ilegal: i) la construcción de circuitos diferenciados de clientela; ii) la preferencia por entidades financieras con presencia nacional, fiscalizadas por las autoridades y iii) minimizar el contacto con clientes sospechosos y emprendedores cuyo dinero es de origen desconocido. Sin embargo, al momento de gastar el dinero esta distanciación se vuelve más difícil ya que la circulación del dinero en el mercado disuelve su origen como veremos a continuación.

\section{Historias del dinero gastado en la ciudad de Pichari}

Los actos de consumo cotidiano raramente ocurren más allá de Pichari ya que el tiempo que se invierte en transportarse hacia una ciudad intermedia no se justifica en el caso de compras de productos de primera necesidad como alimentos, vestimenta e incluso en compras al por menor de electrodomésticos, materiales de construcción y productos tecnológicos. Esto favorece el establecimiento de redes de soporte de las actividades económicas ilegales entre aquellos comerciantes legales e informales en la ciudad, ya que consideran que la única forma de mantener y expandir sus negocios es tener clientes con ingresos vinculados al narcotráfico o a la lucha contra las drogas.

9 Una poza de maceración es una instalación en la que se produce pasta básica de cocaína. 
Esto hace que las fronteras entre los circuitos económicos legal, informal e ilegal sean porosas y las circulaciones entre los mismos se realicen casi sin barreras. El mercado regula las interacciones de consumo, consideraciones como los costos de transporte, logísticos y de marca influyen en el establecimiento de los precios de los bienes y servicios en la ciudad. El estándar de consumo es el consumo urbano en un mundo globalizado. En sucesivas operaciones el dinero gastado de algunos se convierte en el dinero ganado de otros, el dinero que pasa de mano en mano se conecta así con diferentes piezas de dinero en la ciudad.

Las transacciones monetarias son más importantes que las prácticas de trueque o regalos de bienes y servicios. Se intercambia usando dinero en efectivo, en moneda local y extranjera. Es una economía local dinámica, donde el mercado satisface los diferentes tipos de necesidades de los habitantes locales. Esto es lo que trataré de ilustrar a través de tres historias que muestran la circulación de pequeñas cantidades de dinero en la ciudad.

La primera historia se desarrolla en la plaza central de Pichari. La plaza es el lugar central de la vida pública del distrito de Pichari. Según la hora del día y el momento del año tiene múltiples usos: cancha de vóley o fulbito, anfiteatro para ceremonias, pista de patinaje, salón de exhibición de los juguetes de moda, paseo para enamorados, discoteca improvisada para mototaxistas, restaurante al paso para transeúntes, reino del comercio ambulante de golosinas, pasarela improvisada para mostrar las últimas adquisiciones en el guardarropas, entre otros. La plaza es también el centro administrativo de la ciudad, allí se encuentra la sede de las diferentes instituciones públicas. La plaza se convierte por lo tanto es una sala de espera para los diversos trámites que los ciudadanos deben realizar en estas instituciones. Durante el día y la noche, es un lugar animado y transitado, el centro neurálgico de la ciudad. La plaza es también un lugar de reunión, tanto de trabajo como de amistad. La plaza en un espacio de encuentros, como el que presencie en enero del 2016:

Estaba sentada en una de la bancas en una de las rotondas de la plaza. A mi lado un hombre a quien llamaremos Enrique. Él acaba de llegar a Pichari, está esperando a su amigo Aurelio con quien ha quedado en encontrarse a las $7 \mathrm{pm}$ en la plaza para conversar un rato. Ambos son ingenieros civiles y viven en Huamanga, están en Pichari porque la Municipalidad les debe dinero desde el año pasado [2015] y han tenido que venir a cobrarlo personalmente. Es la segunda vez que los amigos tienen que venir a gestionar su pago por problemas administrativos. A pesar de la modernización administrativa y la llegada del servicio de internet a la zona hace varios años, las 
gestiones en la municipalidad se hacen de manera personal. El desorden administrativo y la poca profesionalización de la burocracia local hace que el seguimiento personal de muchas de las gestiones sea necesario para llega a concretar contrataciones, pagos y otros trámites. Los amigos han venido en tiburón, camionetas privadas que hacen la ruta Huamanga - Pichari. Se han demorado por la tranquera ${ }^{10}$ en la carretera. Llegando se hospedaron en un hotel cercano a la plaza, comentan que los precios son más cómodos ahí. Las llaves de sus cuartos tienen la forma de una hoja de coca. En la plaza, los dos amigos compran una gaseosa y siguen su conversación. Enrique recibe una llamada en su Smartphone, al parecer es una mujer quien le pregunta si ya llegó a la ciudad. Él le cuenta rápidamente la historia y la situación en la que va su pago: "mañana tengo que ir temprano a la Municipalidad". Esa noche la invita a encontrarse en un pub cercano. Los amigos conversan un rato más sobre la ruta, el fútbol y otras cosas. Quedan en verse al día siguiente y se despiden. (Notas de campo, Pichari, enero 2016")

Los personajes de esta historia son dos profesionales que obtienen sus ingresos en la esfera legal: un sueldo de una institución pública. Las obras realizadas por el gobierno local gracias al dinero del canon han sido un importante dinamizador de la economía. Esto ha atraído a profesionales de las provincias del VRAEM que pueden llegar a ganar sueldos de entre 3 mil y 5 mil soles ${ }^{11}$ por trabajar por temporadas en los diferentes proyectos de infraestructura y productivos que realiza la municipalidad. A pesar de siempre estar en búsqueda de empleo en diferentes instituciones públicas y privadas, el dinero que ganan es de origen legal. Las conexiones con las otras esferas económicas comienzan a hacerse evidentes en la manera en la que gastan ese ingreso legal. En primer lugar el pago del transporte (tiburón), dependiendo de la época puede ser entre 60 y 100 soles. A pesar de ser vehículos asociados en una cooperativa, ninguno emite recibo. Los pagos se realizan en efectivo directamente al conductor al concluir el trayecto. Parte de esta actividad se encuentra en la esfera de la economía informal. Además el origen del capital para comprar estos vehículos es de origen incierto. Tigre, quien actualmente es conductor de este tipo de vehículos me cuenta:

10 En Pichari se le dice tranquera al cierre de la carretera por obras que se realizaban en la carretera Quinua - San Francisco y que limitaba el transito de vehículos a ciertas horas del día durante algunos meses en 2015 y 2016.

11 Sueldos expresados en moneda local, equivalentes a sueldos entre 920 y 1500 dólares americanos en 2016. 
Tuve que sacar un préstamo mientras trabajaba en [institución pública en Pichari], tenía como presentar papeles de trabajo. Lo saqué en 2009 y sigo pagándolo, cuando hacia trabajar el carro, todo lo que ganaba iba a pagar el préstamo, ahora ya la cuota es menos. Pero a la cooperativa a veces llegan jóvenes con 24, 25 años y tiburón del año pasado. No les vamos a preguntar pero ya te imaginas como han hecho [para conseguir el vehículo]. Las camionetas se maltratan en el camino, la ruta a Puerto Ene es menos dura que la ruta a Huamanga, por eso prefiero no ir hasta allá. Si trabajas tu carro todos los días, en uno o dos años ya se te malogra. Pero acá siempre llegan carros nuevos (Notas de campo, Pichari, junio 2015).

Una camioneta Toyota Hilux cuesta entre veinte mil y treinta mil dólares, y es uno de los vehículos más populares del valle ya que resisten mejor las vías locales, especialmente en época de lluvia. En la ciudad también hay varios talleres mecánicos de autos y motocicletas, algunos que anuncian que se especializan en atención a Hilux, aunque ninguno es filial oficial de Toyota. Algunos son formales y otros informales, pero estos establecimientos también forman parte del circuito de circulación del dinero.

El segundo tipo de gasto que realizan ambos amigos es en alojamiento. El hotel en el que se quedan fue inaugurado hace unos meses, en una de las principales avenidas de la ciudad. Es una construcción de cuatro pisos, con acabados. Los vecinos comentan que se realizó en menos de un año. El hotel da buenos precios con relación a la calidad de sus habitaciones: desde 30 soles la noche en un cuarto con baño propio, 10 soles más barato que otro de los principales hoteles de la ciudad. Aunque los rumores en la ciudad hablan de los vínculos del propietario con el lavado de activos y que puede que sea un negocio de fachada, lo cierto es que no parece haber una investigación abierta aunque los funcionarios públicos que van a Pichari en comisión de servicios prefieren evitarlo. Sin embargo, para el resto de visitantes de Pichari, como en el casos de estos ingenieros, la decisión de donde hospedarse parece basarse en la relación calidad/ precio.

El hospedaje también se paga en efectivo, este tipo de establecimiento da boleta o factura cuando se le pide pero no siempre. Ello a pesar de que varios de estos establecimientos tenían pegado en sus recepciones afiches de SUNAT (Superintendencia Nacional de Aduanas y de Administración Tributaria) sobre una campaña que incentivaba al consumidor a pedir su boleta. Sin embargo, en el caso de aquellos negocios de fachada, es lógico que otorguen comprobantes de pago, ya que como lo explicaba un oficial de policía especializado en el tema 
de lavado de activos, la clave para reinsertar dinero de origen ilegal a la economía legal a través de este tipo de negocios es emitir boletas y facturas a clientes inexistentes. Esto es aún menos sospechoso si el establecimiento logra tener un movimiento de clientela importante, ya que se confunden el dinero de los ingresos por ventas de origen legal con dinero ilegal proveniente de algún delito, en la zona principalmente el narcotráfico.

El tercer rubro en el que ambos amigos gastan dinero es en diversión, tienen planeado salir a un pub en la noche. Sin embargo, el detalle de cómo funciona la circulación de dinero en los establecimientos de entretenimiento (discotecas, pubs, karaokes) lo ejemplificaré mejor con la siguiente historia.

La segunda historia ocurre en la discoteca Stylos, la discoteca más grande de la ciudad con una capacidad para por los menos 150 personas, aunque podrían entrar hasta 300. Karina, la dueña de la cafetería, me abre generosamente las puertas de su casa ${ }^{12} \mathrm{y}$ me propone salir esa noche a divertirnos en la ciudad. A continuación presento el relato de esa noche de fiesta en Pichari:

Stylos es una discoteca de dos pisos que funciona todos los días en Pichari. La entrada no cuesta para las mujeres, para los hombres depende de la hora. El local se ubica a pocas cuadras de la plaza, y ello lo diferencia de otros establecimientos de entretenimiento ubicados en la zona rosa de la ciudad. En Stylos la fiesta es mixta: hombres y mujeres pueden ir y son tratados por igual como clientes.

Paso por Karina, llegamos a las 11 de la noche a la discoteca, queda muy cerca de su negocio. En la entrada hay una agente de seguridad de la discoteca que realiza el control de los bolsos y los bolsillos de los clientes, está prohibido entrar con comida, bebida o armas. Entrando vamos directamente en el segundo piso, junto al bar. Karina me comenta que esa es la mejor ubicación, abajo es la pista de baile, pero Karina me dice que allí está muy inundado y que aparte "va cualquiera". La discoteca es un sauna, música, luces y humo se conectan para generar un ambiente festivo donde se combinan sayas y cumbias. En la discoteca nos encontramos con Max y Christian, dos dueños de restaurante locales quienes amablemente nos invitan una cerveza. No sería educado rechazarla, invitaremos la próxima ronda. La cerveza que ello toman es de la marca "corona" y cuesta 10 soles cada botella personal. Ellos piden corona toda la noche sin problemas.

12 Los agradecimientos son particularmente importantes para aquellas personas que en Pichari apostaron por abrirme las puertas y acompañarme en mis recorridos por la ciudad. 
A nuestro lado hay dos grupos, en ambos Karina tiene conocidos. El primer grupo, me comenta, es personal de la Policía Nacional que ha salido a distraerse en su día de franco. Es un grupo de jóvenes y señores alrededor de algunas botellas de cerveza "Pilsen" en el suelo (la Pilsen también está 10 soles, pero es una botella grande). Del otro lado hay otro grupo, un señor mayor saluda a Karina. Ella me presenta, es un grupo de ingenieros que trabajan consorcio vial que está ejecutando obras en la zona. También han venido a distraerse y bailar un rato. Algunos de ellos toman Pilsen, otros corona, también nos invitan una botella. Charlamos un rato y luego se van. Los barman están atentos a los pedidos, pero siempre cobran por adelantado en efectivo. La discoteca se va llenando conforme avanza la noche. Como bien lo señaló Karina, los baños del primer piso están inundados y también la pista de baile, pero a nadie parece importarle. Sigue la fiesta. Bailamos y charlamos un rato más hasta que llegó la hora de irse. 2am: está lloviendo afuera. Los amigos de Karina nos embarcan en uno de los mototaxis de la entrada, le dicen al chico que tenga cuidado y que nos lleve sanas a nuestras casas. 3 minutos después llegó al hotel. (Notas de campo, Pichari, enero 2016)

Esta historia muestra por una parte como circula el dinero en la noche Picharina y como se va mezclando el dinero de origen diferente a través del consumo en un solo establecimiento. En Stylos todos éramos consumidores, sin embargo nuestro dinero no provenía de la misma fuente. Karina, Max y Christian gastaban en la discoteca el dinero que habían ganado en sus negocios. El grupo de policías que se divertían a nuestro lado gastaban el dinero de su salario. El grupo de ingenieros del Consorcio vial también gastaban el dinero proveniente de sus sueldos pagados por una empresa privada pero pagado por ejecutar una obra pública, por lo que indirectamente el origen del dinero es el Estado. Por mi parte el dinero provenía de mis ahorros y de la Beca otorgada por la universidad. Hasta ahora el origen del dinero de estas personas es la esfera legal. Sin embargo, como la propia Karina me señala que en el piso de abajo va "todo el mundo", tanto empleados de comercios, mototaxistas, agricultores, personas de otros distritos. Todo el que pueda pagar una noche de fiesta. Stylos tiene oferta para diversos bolsillos. Ella también me cuenta que una vez tuvo un problema en la discoteca:

Había venido con mis amigas a bailar. Estábamos tranquilas conversando y bailando. Se nos acerca un tipo, más alto que yo y me invita a bailar. Le digo 
que no. A los cinco minutos se aparece con una botella de cerveza a querer tomar con nosotras. De nuevo le decimos que no. El tipo se comienza a desesperar y a ponerse saltón. Unos amigos nos ven y vienen a hacernos compañía. El tipo se aleja, se va abajo, pero al final de la noche me lo cruzo en la puerta. Estaba borracho y quería volver a entrar. Los guardias le decían que no y le impedían el paso. Ahí el tipo se va al medio de la pista y saca un arma. Nos metimos de nuevo a la discoteca hasta que llego Serenazgo y la Policía y se lo llevo. Felizmente no paso nada pero realmente tu no sabes con quien te puedes cruzar. (Notas de campo, Pichari, enero 2016)

Ella misma me señala que no es común que las personas anden armadas y que probablemente ese hombre iba armado porque "estaba metido en algo". Pero por precaución ella prefiere quedarse en la parte de arriba de la discoteca y solo socializar con aquellos que conoce previamente. Las luces y el calor dificultan la conversación, es difícil llegar a "conocer" a alguien en esas condiciones. Por ello Karina tampoco acepta invitaciones de bebidas de extraños.

Durante la noche vi que la gente se acercaba a la barra y compraba diferentes bebidas. Lo que más parece venderse es la cerveza, la mayoría de personas pagan en efectivo, ningún comprobante es emitido. También hay la posibilidad de pagar con tarjeta, pero esa noche la máquina no está funcionando, solo efectivo. De nuevo, pequeñas cantidades de dinero (Desde 10 hasta 100 soles por compra) circulando de la mano de los consumidores a la mano de los negocios locales. Esa es la dinámica económica de un sábado cualquiera, ese día no hay una conmemoración especial ni música en vivo, solo "una noche tranquila" para el negocio como me dice Karina. Una noche que parece tener bastante movimiento económico.

Tanto la primera como la segunda historia nos muestran la importancia de la circulación de dinero en efectivo en el dinamismo económico de la ciudad. El efectivo es la principal moneda de intercambio ya que muy pocos comercios locales permiten pagar con tarjeta. En Pichari existe un Banco de la Nación y algunos locales de cajas de ahorros.

La bancarización de la economía ha avanzado en el distrito, principalmente a través de las instituciones financieras locales (cooperativas y cajas de ahorro). Sin embargo, como la siguiente historia ilustra, incluso cuando el dinero no circula de mano en mano, dentro del sistema financiero, este puede terminar conectando las esferas económicas legales e ilegales. La siguiente historia me la contó Tigre, transportista en Pichari, una de sus pasajeras frecuentes en la ruta 
hacia Puerto Ene lo comentó los problemas que había tenido con una cooperativa de ahorro:

Emilia es una comerciante de chicha que todos los días hacía el trayecto hacía Puerto Ene. Emilia prefiere vender su chicha en Puerto Ene porque el valor de un vaso de chicha era de dos soles, el doble de lo que le pagan en Pichari. Todos los días va en alguna de las camionetas que hace la ruta, vende su mercadería y regresa con sus ganancias. Ella ahorraba su dinero en una cooperativa de ahorro y Finanzas: "Mujeres Emprendedoras". Esta cooperativa es una pequeña asociación que apareció hacia el año 2014 en Pichari. Emilia había juntado casi 10 mil soles que puso en una cuenta en la cooperativa. Era el dinero para su hija. Después de unos meses quiso sacar una suma de dinero. Tigre la encontró fuera del local de la cooperativa, llorando y le preguntó: “¿Que ha pasado señora?” a lo que Emilia respondió: "Yo tengo mi plata, y no me quieren devolver, Son 15 dias que me están paseando, mañana, mañana". Tigre también estaba allí porque una de sus hijas de quince años había ahorrado 600 soles en la cooperativa. Él se puso fuerte y les dijo: "si no me dan mi plata llamo a Indecopi", luego de unas semanas consiguió recuperar el dinero. En cambio la señora Emilia, al no tener como acreditar el origen del dinero no quiso recurrir a la vía del reclamo formal. Tigre no está seguro si Emilia recuperó el dinero, pero me dice que lo más probable es que lo haya perdido para siempre. (Notas de campo, Pichari, junio 2015)

¿Qué nos dice esta historia sobre el dinero que circula y se ahorra en Pichari? En primer lugar, nos muestra la circulación del dinero entre el campo y la ciudad, el dinero llega a Pichari desde una zona donde el principal movimiento económico está asociado a una actividad ilegal: la zona de Puerto Ene. Según Tigre, en esa época el movimiento económico en Puerto Ene era importante, era el nuevo centro del "negocio". Las transacciones ligadas al naroctráfico acontecían en ese lugar tanto de día pero principalmente de noche: compra y venta de insumos químicos, de hoja coca seca, de motores, de cemento, todas las transacciones imaginables. El dinero en efectivo circulaba en cantidad, tanto en soles como dólares en la zona, me comenta Tigre. Las autoridades pocas veces llegan allí.

Dada la cercanía de Puerto Ene (alrededor de dos horas de camino desde Pichari), muchos comerciantes ambulantes de comida van diariamente a ofrecer sus productos. El origen del dinero que se gasta para adquirir sus productos muchas veces es de proveniencia ilegal, puede haberse obtenido por la venta de 
hoja de coca o insumos químicos sin autorización. La transacción de compra venta con una ambulante como Emilia hace que el dinero circule hacia la esfera informal. Emilia no es una emprendedora en el sentido formal del término, no está registrada como tal, no declara sus ingresos, no entrega ningún tipo de comprobante de pago.

En segundo lugar, esta historia nos muestra lo que sucede con el dinero en el sistema financiero local. Emilia regresa con ese dinero a la ciudad, donde reside con su hija, y lo ahorra en efectivo en su vivienda hasta que decide ingresarlo al circuito financiero, a una cooperativa de ahorro. Este es un rubro que ha crecido en la última década, según declaraciones de diversas autoridades (municipales y policiales) existen entre 25 y 30 cooperativas funcionando en el distrito de $\mathrm{Pi}$ chari. Durante mis observaciones de campo pude ubicar al menos 20 locales de establecimientos de este rubro.

Las cooperativas y cajas de ahorro locales son muy populares y varios de los habitantes locales tienen dinero ahorrado en más de una de estas entidades. Durante el año 2015 se reportaron varios casos de estafa: cooperativas que funcionaban por algunos meses para captar el mayor dinero posible de sus ahorristas, ponían condiciones para invertir el dinero a plazo fijo, y luego desaparecían con el dinero.

Existe poca fiscalización de esta actividad en la zona, la Sociedad de Banca y Seguros (SBS) no supervisaba (hasta junio del 2018) a estas entidades financieras y la Municipalidad recién comenzó a realizar operativos inopinados de supervisión en el año 2016, por lo que es un mercado particularmente vulnerable a las estafas como la que le sucedió a Emilia. Su dinero de origen informal ingresó a un circuito financiero que a pesar de ser legal es bastante informal, y terminó convirtiéndose en dinero robado, por lo tanto dinero ilegal. En otros casos, cuando las cooperativas sirven como negocios de fachada, como he explicado anteriormente, el dinero de origen legal e informal terminan combinándose en las cuentas de la cooperativa con dinero de origen ilegal, reingresando todo en la esfera legal de la economía.

\section{Dinero ganado y dinero gastado en la ciudad cocalera: la disolución de las valoraciones morales en el mercado}

¿Qué tienen en común los relatos anteriores? En las tres el dinero circula entre las diferentes esferas de la vida económica de la ciudad y va borrando implícita o explícitamente las barreras morales entre las diferentes fuentes de dinero, entre "el dinero sucio" y "el dinero honrado". Si bien varios de los actores 
locales se preocupan por ganar, en la medida de lo posible, su dinero de manera "honrada", como ellos mismos lo señalan, es poco lo que pueden hacer para que su dinero gastado no termine por confundirse e incluso alimentar la esfera económica ilegal. En todos los relatos el dinero circula y se transforma, ya sea en dinero gastado, en dinero debido, en dinero ahorrado, en dinero perdido. Todos con un sentido inicial distinto para las personas que participan de estas transacciones, pero que termina conectándose y mezclándose en la economía de mercado.

La figura $\mathrm{n}^{\circ} 1$ resume las operaciones de transformación del dinero que operan en los escenarios detallados anteriormente.

Figura 1 - Transformaciones del dinero ganado al dinero gastado en la ciudad cocalera

\section{Dinero Ganado}

- de origen estatal (esfera formal)

- de origen del sector privado formal

(esfera formal)

- de origen del sector privado informal

(esfera informal)

- de origen ilegal ligado a los eslabones de la cadena del tráfico ilciito de

drogas cocaínicas (esfera ilegal)

\section{Dinero Gastado}

- en el consumo de bienes y servicios (cesfera formal o informal)

- en la inversión o ahorro en el sistema

financiero (esfera formal o informal)

- dinero perdido por estafas o robos

(esfera ilegal)

- dinero donado (esfera informal o

ilegal)

Fuente: Elaboración propia

Las operaciones que se realizan con el dinero en cada uno de estos escenarios transforman el dinero ganado tanto de manera legal o ilegal en dinero cuyo uso es visto como legítimo, o, al menos, aceptado socialmente por su utilidad y conexión con los circuitos formales e informales. La pregunta que surge entonces es si el dinero se gasta sin perjuicio a uno mismo o a otros. Como lo vimos en los relatos, se valoriza la reinversión en actividades legales (como agricultura, comercios y servicios) y no se cuestiona el origen del dinero que permita financiarla. Si el dinero financia el crecimiento de los emprendedores locales y el bienestar de los habitantes de la ciudad, permitiéndoles tener una mejor calidad de vida, entonces no se cuestiona su origen. 
En tanto que, como en el caso de las prostitutas analizado por Hoigard y Finstad (1992) si existen gastos que se consideran moralmente inaceptables aunque comunes en la práctica. Es el caso de lo que se denomina "dinero fácil” abordado en detalle por Aronés (2016). Este es un dinero que se gasta rápidamente en gastos de consumo inmediato (en prostitución, drogas, alcohol, bienes tecnológicos, entre otros) y se asocia generalmente con los jóvenes de la ciudad involucrados en el narcotráfico. Si bien no pude observar directamente el gasto de este dinero, ya que varias de estas actividades se realizan en locales en lo que se prohíbe la entrada de mujeres y más aún foráneas, varios habitantes de la ciudad me mencionan que "el dinero que rápido viene, rápido se va". Estos habitantes anclados en la esfera legal no critican necesariamente como los jóvenes ganan su dinero, si el uso del mismo, mencionándome que la juventud no sabe ahorrar ni gastar su dinero.

¿Qué termina construyendo el dinero en la ciudad? Redes de circulación de dinero entre las diferentes esferas económicas que coexisten en la ciudad y de los cuales ninguno de los habitantes puede escapar. Incluso sin estar consciente o sin desearlo su dinero puede terminar mezclándose con dinero de origen ilegal, ya que ambos pueden ser gastados en los mismos establecimientos o puede alimentar algún negocio vinculado al lavado de activos. El mercado termina borrando las fronteras entre lo que al principio parece fácil de diferenciar: dinero legal y dinero ilegal. Así, si en un inicio podíamos comprender el dinero ganado en Pichari en base a lo planteado por Zelizer y Wilkis, en el transcurso de las transacciones económicas el origen del dinero se va anonimizando y la visión propuesta por Simmel cobra más fuerza.

Por un lado, nos queda la incertidumbre sobre cómo se operó concretamente nuestra conexión con la esfera ilegal. Muchos de los habitantes locales optan por no saber cómo opera esa conexión. "No preguntar más de la cuenta", "no saber más de lo debido", "no hablar de lo que no se debe" son reglas tácitas que ordenan la vida de los habitantes en su relación con el dinero. Si no sabemos de dónde viene el dinero o como se vincula con la ilegalidad podemos seguir siendo parte de las transacciones que con él se realiza. La sospecha y la complicidad, voluntaria o involuntaria, de todos con el funcionamiento de las actividades ligadas al narcotráfico animan a los habitantes a desarrollar mecanismos de legitimación moral del dinero que circula en la ciudad.

Estas reglas no las aprendí haciendo trabajo de campo sino cuando trabajaba en la ciudad, como una practicante de una institución pública, son consejos que te van dando los colegas, amigos y que forman parte del "sentido común local". En conversaciones con antiguos colegas durante el trabajo de campo, la 
reflexión volvió a surgir. Renzo, ingeniero con muchos años de experiencia en la zona me dijo: "No hay como, acá todos terminamos siendo cómplices del narcotráfico". Para aclarar esa afirmación, Renzo me dice:

Acá somos tontos útiles, hacemos como que luchamos contra el narcotráfico, damos ayudas del PROVRAEM ${ }^{13}$, concientizamos a la gente, hacemos nuestra chamba. Pero por el otro lado tienes a los militares denunciados por las avionetas, el PROVRAEM aceptando hectáreas viejas de coca, y la policía capturando a casi nadie. La SBS ni la Contraloría vienen a fiscalizar. Nosotros solos no podemos evitar que todo esto pase. Tenemos que vivir acá, y para eso a veces hay que hacerse la vista gorda (Notas de Campo, Pichari, enero del 2016)

Para poder continuar con las transacciones económicas cotidianas en la ciudad, aquellas personas que operan principalmente en la esfera económica legal utilizan dos mecanismos. En primer lugar hacer énfasis en el origen legal de su dinero, fruto de su trabajo y esfuerzo. No es lo mismo el dinero del narcotráfico, el dinero robado por las cooperativas o el salario ganado a fin de mes. La forma en la que se gana el dinero legitima su circulación. Siguiendo la distinción planteada por Wilkis (2013) sobre las piezas de dinero, podríamos denominar a esta pieza de dinero como "dinero honrado". Se trata de una categoría de dinero que expresa una valoración moral sobre la forma en la que se ha ganado dicho dinero, y que le da tranquilidad a la persona que lo usa para gastarlo en el mercado.

Las jerarquías morales locales de aquellos actores que se perciben como fuera de la esfera ilegal incluso los lleva a aceptar o rechazar ciertas piezas de dinero consideradas como "ilegales" e incluso a calificarlas como "dinero sucio". Evitar ciertas transacciones con actores desconocidos o con mala reputación, "Prefiero no asesorar a fulano o prefiero no comerciar con tal otro", son conductas que algunos emprendedores y consultores locales toman al momento de hacer negocios.

Sin embargo, en otros casos, como en los comercios de atención al público, cuando no se puede evitar recibir el dinero de ciertas personas, se opta por ignorar su origen. A este segundo mecanismo, podríamos denominarlo una suerte de "desatención cortés" (Goffman, 1963) económica. En la medida de lo posible, los habitantes locales aprovechan el anonimato que les da la ciudad que les permite ignorar a quien le compran o a quien le venden un producto o

13 Proyecto Especial para el Desarrollo del Valle de los Ríos Apurímac Ene y Mantaro, impulsado por el Ministerio de Agricultura. 
servicio. Si hay un velo de legalidad que cubra la actividad (ya sea por tributar impuestos, tener licencia municipal, tener una buena reputación entre los habitantes) entonces no se hacen muchas preguntas sobre las personas y el dinero que interactúan en estas transacciones.

Así, los actores de estas transacciones "demuestran a través de la mirada [o en este caso del intercambio de dinero] que uno aprecia que la otra persona esté presente (y que uno admite abiertamente haberlo visto), aunque inmediatamente después retire su atención de dicha persona expresándole que no constituye un objetivo especial de curiosidad" (Goffman, 1963: 83). Se establece una relación cortés, incluso cuando se tiene alguna noción o sospecha de que la persona con la que se está intercambiando tiene algún vínculo con una actividad ilegal. Uno de los pensamientos recurrentes entre quienes intercambian con estas personas es qué si las autoridades no los han capturado y nadie les está haciendo problemas, no les corresponden a ellos hacerlos. Si bien es una actitud que se constituye en cada transacción, pueden marcar la actitud entre dos partes en una relación. Así, por ejemplo, existen empleados públicos cuyos jefes conocen que tienen terrenos (dónde cultivan coca) o camionetas (donde han transportado cargamentos ligados al narcotráfico - insumos o drogas) sin embargo no preguntan sobre los cultivos ni los usos del transporte. Se reconoce la existencia de dicha actividad complementaria sin indagar más al respecto. Esa frontera de "desconocimiento" o "desatención" es clave para que toda la economía funcione y las esferas económicas se conecten fluidamente. Es por lo tanto un mecanismo clave para el funcionamiento de la economía local en Pichari.

\section{Conclusiones}

La coca llega a la ciudad cocalera en forma monetaria, moviliza mucho dinero, pero no es la única fuente económica que alimenta la ciudad. La presencia del Estado (y sus diversos organismos) también alimenta la dinámica económica, especialmente si se toma en cuenta el crecimiento de Pichari como centro administrativo en los últimos años. Así, tanto el Estado, el narcotráfico y el sector privado constituyen los motores económicos de la ciudad y dibujan las esferas económicas que en ella conviven: formal, informal e ilegal. Esto no es diferente de lo que sucede en diferentes zonas urbanas y rurales del país dónde existe presencia de economía ilegales.

No obstante, lo que caracteriza la ciudad de Pichari es que crea oportunidades para que el dinero ganado por los habitantes de la ciudad provenientes de diferentes fuentes sea gastado en un circuitos económico que abona al 
crecimiento de la economía local y por lo tanto crean una percepción de prosperidad económica en la ciudad. En Pichari no hay coca, hay dinero. Y es el dinero el que media las conexiones entre las diferentes esferas de la vida social a partir de sus trayectos entre distintas esferas económicas.

Así no es el carácter legal o ilegal del dinero, según lo definido desde una perspectiva normativa lo que hace aceptable el dinero. Las valoraciones morales tras las piezas de dinero ganado (Wilkis, 2013) existentes en la ciudad se hacen en función del aporte que significan para uno mismo, su familia y su comunidad, independientemente del circuito del que provengan. Ya la valoración en torno al dinero gastado se diluye en los actos de consumo en el mercado, resurgiendo solo en casos muy específicos como el del "dinero fácil” de los jóvenes. En un contexto con bajos índices de crimen violento, no se percibe que el narcotráfico sea perjudicial a nivel local, lo que facilita que el dinero proveniente de este circuito sea aceptado en las transacciones monetarias cotidianas.

Las valoraciones sobre los usos del dinero se hacen por lo tanto en función del bienestar que generen a nivel local más que sobre su origen legal o ilegal. En ese sentido el dinero que alimenta circuitos de bares en los que se suscitan peleas callejeras o que contribuyen al crecimiento de la zona rosa de la ciudad es percibido como un gasto negativo. En estos casos, las fronteras entre lo legal y lo ilegal vuelven a cobrar sentido y la población local espera una actuación más proactiva de las autoridades para el control de estas actividades. Se espera que los esfuerzos de las autoridades se dirijan a fiscalizar y cerrar este tipo de negocios considerados como perniciosos en vez de enfocarse principalmente en contrarrestar el narcotráfico. Se construye así un discurso en torno a la moralidad del narcotráfico que no está asociado a las valoraciones normativas que el Estado impone sobre la actividad sino ante los efectos que la población percibe directamente.

Por el momento, son los aportes positivos de la actividad como motor económico los que prevalecen sobre los problemas que genera. A nivel local se percibe que el narcotráfico contribuye al crecimiento económico y a la generación de nuevas oportunidades de bienestar lo que compensa los efectos negativos en un sector de la juventud que no se percibe como mayoritario. Sin embargo esta es una tensión constante y las valoraciones de los actores van cambiando en función de lo que presencian cotidianamente. Esto refleja que la aparente convivencia pacifica entre las esferas legales e ilegales en Pichari si tiene contradicciones y no es tan fluida como podría aparecer en un inicio. Estas tensiones puede terminar por romper el frágil equilibrio existente y hacer evolucionar el escenario local hacia un contexto más adverso a la actividad ilegal. Así por 
ejemplo, en México, las autodefensas y otras asociaciones de vigilantismo se organizaron tanto para combatir la violencia generada por el narcotráfico pero también para imponer un cierto orden moral en la que también se combatiesen actividades perniciosas como el consumo de drogas o la prostitución (Zizumbo Colunga, 2015). El choque entre los ordenes morales puede ser un recursos para la movilización ciudadana contra la presencia de actividades ilegales.

\section{Referencias}

AGUDO SANCHÍZ, Alejandro; ESTRADA SAAVEDRA, Marco. (Trans)formaciones del estado en los márgenes de Latinoamérica: imaginarios alternativos, aparatos inacabados y espacios transnacionales. México D.F, Universidad Iberoamericana, 2011.

ALVES MULLER, Lucía Helena. Mercado exemplar: um estudo antropológico sobre a Bolsa de Valores. Porto Alegre, Zouk, 2009.

ALVES MULLER, Lucía Helena; WILKIS, Ariel. Etnografias de práticas econômicas. Civitas. Porto Alegre, v. 10, n. 3, 2010, pp. 373-375.

ARONÉS, Mariano. Enseñar y educar en una zona de conflicto: El caso de los profesores/ as del valle de los Ríos Apurimac, Ene y Mantaro. Lima, Documento de Trabajo CIES, 2016.

BARROS, Macarena; OSSANDÓN, José. Prácticas financieras en torno al uso del crédito en la industria del retail de Santiago. In: Destapando la caja negra/Sociologías de los créditos de consumo en Chile. Santiago de Chile: Instituto de investigación en ciencias Sociales (icSo), Universidad diego Portales, 2012, pp. 113-132.

DAMATTA, Rodrigo; SOAREZ, Eduardo. Águias, Burros e Borboletas: Um Estudo Antropológico do Jogo do Bicho. Rio de Janeiro, Rocco, 1999.

FELTRAN, Gabriel De Santis. O valor dos pobres: a aposta no dinheiro como mediação para o confl ito social contemporâneo. Caderno CRH. Salvador, v. 27, n. 72, 2014, pp. 495-512.

FIGUEIRO, Pablo. "Clientes" y "jugadores": el fiado en una agencia de lotería. Buenos Aires, Documento de Trabajo IDAES, 2012.

FISCHER, Edward. Cash on the table: markets, values, and moral economies. Santa Fe, School for Advanced Research Press, 2014.

GOFFMAN, Erving. Behavior in public places. New York, The Free Press, 1963.

GRANOVETTER, Mark S. The streght of Weak ties. American journal of sociology. Chicago, v. 78, n. 6, 1973, pp. 1360-1380.

GUYER, Jane. Marginal Gains. Chicago, The University of Chicago Press, 2004.

HART, Keith. The Memory Bank. London, Profile Books, 2007.

HOIGARD, Cecilie; FINSTAD, Liv. Backstreets: Prostitution, Money, and Love. Pennsylvania, Penn State University Press, 1992. 
INGHAM, Geoffrey. The Nature of Money. Cambridge, Polity Press, 2004.

LOMNITZ, Larissa Adler De. Cómo sobreviven los marginados. México D.F, Siglo XXI Editores, 1978.

MARCUS, George. Ethnography in/of the World system: The Emergence of Multi-Sited Ethnography. Annual Review of Anthropology. Palo Alto, v. 24, 1995, pp. 95-117.

MAURER, Bill. The Anthropology of Money. Annual Review of Anthropology. Palo Alto, v. 35 , n. 1, 2006, pp. 15-36.

MAUSS, Marcel. Essai sur le don. Quadrige- ed. Paris, PUF, 2016 (1925).

MAYER, Enrique. Casa, chacra y dinero: Economías domésticas y ecología en los Andes. Lima, IEP, 2004.

MONTES DE OCA, Laura Beatriz. Entre activistas, funcionarios e industriales. Aplicación de la etnografía - enfocada y política - en escenarios de gobernanza. Nueva Antropología. México D.F, v. 28, n. 83, 2015, pp. 25-46.

MÜLLER, Lúcia Helena. Bancos na favela: relações entre agências bancárias e moradores de uma região urbana alvo de políticas de "pacificação". Tempo Social. São Paulo, v. 29, n. 1, 2017, p. 89.

OEA - Organización de Estados Americanos. La economía del narcotráfico. Washington D.C., 2013.

PARRY, J; BLOCH, M. Money and the Morality of Exchange. American Ethnologist. [s. 1.], v. 18,1996, p. 631.

SIMIAND, François. La monnaie, réalité sociale. In: Critique sociologique de l'économie. Paris, PUF, 2006, pp. 215-279.

UNODC. Monitoreo de cultivos de Coca 2015. Lima, UNODC - DEVIDA, 2016.

VALENCIA, Sayak. Capitalismo Gore. Ciudad de México, Paidos, 2016.

VILLARREAL, Magdalena. Mujeres, finanzas sociales y violencia económica en zonas marginadas de Guadalajara. Guadalajara, Instituto Jalisciense de las Mujeres y el Instituto Municipal de las Mujeres en Guadalajara, 2009.

WILKIS, Ariel. Don, dinero y moral en el análisis de un circuito filantrópico. Buenos Aires, Documento de Trabajo IDAES, 2009.

WILKIS, Ariel. Las sospechas del dinero. Buenos Aires, Paidos, 2013.

ZELIZER, Viviana. El significado social del dinero. Buenos Aires, Fondo de Cultura Económica, 2011.

ZIZUMBO COLUNGA, Daniel. Taking the Law into Our Hands: Trust, Social Capital, and Vigilante Justice. PhD Thesis, Political Science, Vanderbilt University, 2015.

Recebido em 06/11/2017

Aprovado em 17/10/2018 


\section{Como citar este artigo:}

CASTILLO, Sofía Isabel Vizcarra. El dinero: organizador social de la ciudad de

Pichari. Contemporânea - Revista de Sociologia da UFSCar, v. 9, n. 1, jan.- jun. 2019, pp. 173-198. 